\title{
An Evaluation Method for Effective Prestress of Simply Supported Prestressed Concrete Beams with Breathing Cracks
}

\author{
Wenlong Guo, ${ }^{1,2}$ Peng Liang $\mathbb{D}^{1}{ }^{1}$ Hexu Liu, ${ }^{3}$ Y. Frank Chen, ${ }^{4}$ and Xiaojin Zhao ${ }^{5}$ \\ ${ }^{1}$ School of Highway, Chang'an University, Xi'an, Shaanxi, China \\ ${ }^{2}$ Shanxi Transportation Technology Research \& Development Co., Ltd., \\ Shanxi Key Laboratory of Bridge Engineering Disaster Prevention and Mitigation, \\ Key Laboratory of Highway Construction \& Maintenance Technology in Loess Region, Taiyuan 030006, Shanxi, China \\ ${ }^{3}$ Department of Civil and Construction Engineering, Western Michigan University, Kalamazoo 49008-5316, MI, USA \\ ${ }^{4}$ Department of Civil Engineering, The Pennsylvania State University, Middletown 17057, PA, USA \\ ${ }^{5}$ Shanxi Transportation Technology Research \& Development Co., Ltd., \\ Shanxi Key Laboratory of Bridge Engineering Disaster Prevention and Mitigation, Taiyuan 030006, Shanxi, China \\ Correspondence should be addressed to Peng Liang; bridgedoctor@qq.com
}

Received 9 August 2020; Revised 13 November 2020; Accepted 12 December 2020; Published 7 January 2021

Academic Editor: Dan Ma

Copyright (C) 2021 Wenlong Guo et al. This is an open access article distributed under the Creative Commons Attribution License, which permits unrestricted use, distribution, and reproduction in any medium, provided the original work is properly cited.

Loss of effective prestress and accurate detection of actual stress in existing precast prestressed concrete bridges are two major challenges in the bridge industry. In this respect, this research aims at an improved method for the critical decompression moment (DM) test of cracked sections depending on the stress change rate of tensile rebars. A calculation method for total effective prestress of prestressing strands in the tensile region is derived with the assumption of the plane section and pre-decompression elastomer. The proposed method is verified by laboratory tests on beams and numerical analysis and by addressing effective prestress issues of existing simply supported beams. The determination results of the critical decompression state show that the proposed method (i.e., the stress change rate of tensile rebars-load curve) is more sensitive and reasonable than the traditional stress increment, i.e., load curve method. The evaluation results of the total effective prestress are more reasonable than the traditional method based on the steel stress relief hole technique or frequency test results. Compared with the existing methods for estimating the prestress using the mid-span deflection or crack width, the proposed method is more reasonable in theory and calculation. It provides a guide for the evaluation and reinforcement of aging bridges.

\section{Introduction}

Prestressed concrete bridges occupy a relative majority position in bridge engineering because of their advantages, such as simple construction, convenient mold casting, and low cost. Due to issues such as low design load, long servicing time, indeterminate estimation of effective prestressing decay effect, and overloading, most of the prestressing concrete bridges in service are cracked at varying degrees. It imposes significant challenges to the bridge technical state diagnosis and accurate reinforcement. Especially for partial prestressed concrete structures where cracking is allowed, the cracked sections are usually located at the mid-span of fully or partially PC beams. Most of the cracks are in the closed state under dead loads while remaining open under live loads. The cracks experience a repeated condition of closing-opening-reclosing-reopening, known as "breathing cracks" [1]. Karayannis and Chalioris [2] introduced the design method of partially prestressed concrete structure based on crack width and proposed the design program and useful chart. The direct design method of partially prestressed concrete beams based on plastic mechanics theory was proposed by Alnuaimi and Bhatt [3] verified on indoor model beams. The prestressing decay phenomenon raises the uncertainties in shrinkage, creep, and load capacity [4-6], making it difficult to estimate the actual remaining effective prestress of the main beam under service. The following 
issue is crucial for exiting bridges and has received increasing attention: how to determine the effective tension of prestressing (P/S) strands at a later stage.

Many scholars have studied the testing methods of the existing stress state of bridges in service. Osborn et al. pointed out that there are some appreciable deviations between measured prestress losses and losses predicted by models provided in codes. However, Halsey and Miller have reported good agreement between predicted and empirically determined losses. Bagge et al. introduced the destructive methods (including crack moment method, decompression load method, and stress relief method) and nondestructive methods (including exposed strand method, drilled hole methods, and saw-cuts method) for residual stress detection of bridges in service. Decompression load, referred to as "DL," is the load that enables cross-sectional internal forces to reach a critical decompression state (in this text, applied load in addition to dead load). And the stress relief technique and decompression load methods were analyzed and tested. Garber et al. [7] conducted experimental research on 30 prestressed beams. The loss of prestress was measured by using vibrating wire gauges embedded in test specimens. The results were compared to those determined using several different estimation procedures, suggested by ACI Committee 423. Civjan et al. [8] introduced an instrument to estimate stress levels in prestress strands in existing members and pointed out that the strand forces were consistently estimated to within ten percent of the actual load. Maji and Negret [9], Ahlborn et al. [10], and Ghorbanpoor [11] detected the prestress loss of $\mathrm{P} / \mathrm{S}$ strands of existing bridges by means of the shape memory alloy (SMA), acoustic emission technology, and magnetic flux leakage principles, respectively. They effectively detected the change in prestress loss. However, there is a drawback that the appropriate sensor equipment must be embedded in the main beam in advance. This is obviously inconvenient when dealing with a large number of bridges. Cawley and Adams [12], Clough and Penzien [13], Saiidi et al. [14], Dall et al. [15], and Housner and Belvin [16] proposed the method to predict the prestress of $\mathrm{P} / \mathrm{S}$ strands based on the natural frequency of the structure. They conducted tests to find the change in the frequency of prestress loss and proposed the modified formula for effective flexural stiffness, $(\mathrm{EI}) \mathrm{e}=(1+1.75 \mathrm{~N} / \mathrm{fe})$ EIg. However, this formula has not been universally recognized by the bridge community. Later, Miyamoto et al. [17] and Kim et al. [18] indicated that the relationship between prestress loss and modal parameter change had not been successfully established. The advantage of the second method is to directly set up the correlation between the resultant force of effective prestresses and the vibration frequency of the main beam. However, the damage degree and prestress level of existing bridges will influence the natural frequency of the structure, and the structural damage identification theory would fail to reach maturity. Therefore, the previous prediction method for effective prestress is deemed not matured. Li et al. [19] proposed a horizontal tension-increment method to find the actual stress in $\mathrm{P} / \mathrm{S}$ strands, and the detection principle is similar to reference [8].
On the other hand, the vertical crack near the mid-span of the main beam is a typical Type I crack in fracture mechanics. The height of the compression zone is the full section height before the closure of the fracture section. If the analysis is carried out according to the converted section method based on the assumption of the plane section in the literature [20], the section properties are the same as that of the uncracked section, and the difference of the influence of closed cracks on the stress field of the section cannot be considered. The traditional finite element method (FEM) needs to constantly update the meshing to simulate the development of cracks, and the preprocessing is very complex and even impracticable. The literature [21-24] analyzes the mechanical properties of structures with cracks by introducing the extended finite element method (XFEM) proposed by Belytschko et al., USA. In this method, step function and split point asymptotic function are introduced to enhance the description of material and deformation discontinuity problems. The approximate displacement solution is obtained under the frame of unit decomposition, which provides a new idea for the analysis of the mechanical properties of prestressed concrete bridges with closed cracks.

In short, although existing literature pertinent to the determination of effective prestress of existing bridges has been well reported, there are still many issues in the accurate determination of the effective preloading of simply supported beams with breathing cracks, and in the analysis of the mechanical performance of the partial prestressed members with closed cracks [25-29]. This paper derives a calculation formula for the total effective prestress of prestressing strands in the tensile region based on the assumption of plane section and pre-decompression elastomer, where the test load for decompression moment (DM) is referred to as "DL" method. The proposed method is verified by laboratory tests and numerical analysis. It provides a guide for the evaluation and reinforcement of aging bridges. The detection principle of the method proposed in this paper is similar to the one used by Bagge et al. Their measured parameters are the displacement across cracks or the increment of concrete strain on the surface, while the measured parameters in this paper are the increment of steel bars stress across the closed cracks. Because the test in this paper is a single point loading at the mid-span section of the test beam, the crack crosses the mid-span tensile zone to foresee the embedded sensor. In the real bridge test, according to the preloading test before the load test, when the closed crack is reopened, the position of the closed crack is marked, and then the protective layer concrete of the outermost reinforcement can be removed artificially at the crack position, and the steel strain gauge is pasted on the surface of the reinforcement at the position of the crack and then the formal loading test can be conducted.

\section{Analysis Principle and Calculation Model}

In prestressed concrete structures with breathing cracks, the cracks are closed under the dead load. The force calculation model of the section is shown in Figure 1. The effective prestress is closely related to the cracking moment of the section. But due to the discreteness of tensile strengths of 

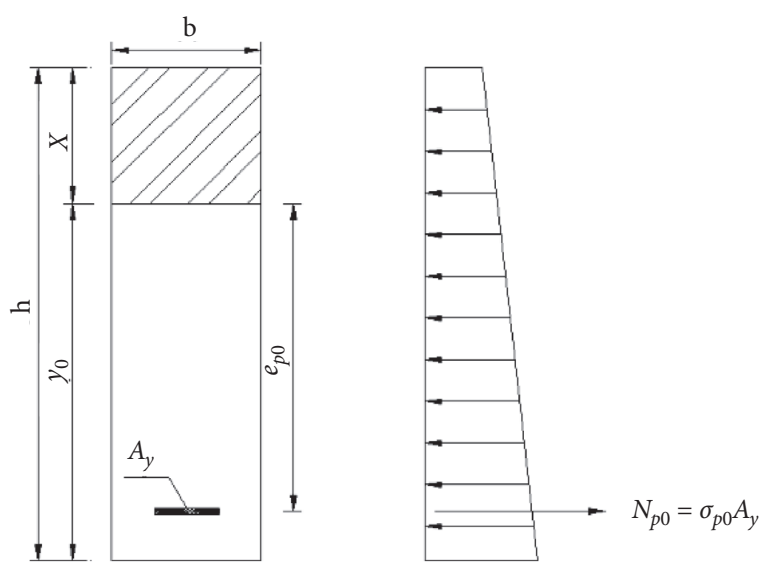

FIGURE 1: Diagram showing the simplified mechanical model.

concrete, it is difficult to estimate the actual effective prestress of the section according to measured cracking moments. When the section with closed cracks is cracked again due to an additional load, there is no concern on the discrete tensile strength as the concrete tensile strain becomes completely disabled in this case. In the case of re-cracking, if the nonlinear effect of the prestressed concrete section with closed cracks is not considered (more discussed in Section 5.2), the cracking moment of the section is approximately equal to the DM. The correlation between effective prestress of $\mathrm{P} / \mathrm{S}$ strands in the tensile region and the measured cracking moment can be established according to the plane section and elastomer assumptions in conjunction with the calculation theory of prestressed concrete beams.

2.1. Principle for Effective Prestress Determination by the Pretensioning Method. Figure 1 shows the simplified mechanical model, when the normal stress of concrete at the center of gravity (c.g.) of the resultant force of $\mathrm{P} / \mathrm{S}$ strands in the tensile region is equal to zero for pretensioned flexural members $\left(\sigma_{p c}\right)$ calculated by $[20,30-32]$

$\sigma_{p c}=\frac{N_{p 0}}{A_{0}}+\frac{N_{p 0} \cdot e_{p 0}}{\omega_{0}}=\frac{N_{p 0}}{A_{0}}+\frac{N_{p 0} \cdot e_{p 0}}{I_{0}} \cdot y_{0}$ with $\omega_{0}=\frac{I_{0}}{y_{0}}$,

$M_{c r}=\left(\sigma_{p c}+\gamma \cdot f_{t k}\right) \frac{I_{0}}{y_{0}}$.

Equation (1) is used to calculate the stress in the tension zone of the prestressed concrete section, while equation (2) is for computing the cracking moment of the prestressed concrete section. In the case of cracked structures, the cracked concrete in the tensile region cannot withstand the tensile strain, especially when the section with closed cracks is decompressed again, causing a lower stress level to be in the elastic range. If there is no nonlinear relation on the cracked section, i.e., $\varepsilon_{t k}=0$ and $f_{t k}=0 \mathrm{MPa}$, then equation (2) can be rewritten as

$$
\begin{aligned}
M_{c r} & =\sigma_{p c} \cdot \frac{I_{0}}{y_{0}}=\left(\frac{N_{p 0}}{A_{0}}+\frac{N_{p 0} \cdot e_{p 0}}{I_{0}} \cdot y_{0}\right) \cdot \frac{I_{0}}{y_{0}} \\
& =N_{p 0}\left(\frac{I_{0}}{A_{0} \cdot y_{0}}+e_{p 0}\right) .
\end{aligned}
$$

Based on equation (3) and considering the critical redecompression state, the effective prestress of $\mathrm{P} / \mathrm{S}$ strands in the tensile region is given by

$$
N_{p 0}=\frac{M_{c r}}{\left(I_{0} / A_{0} \cdot y_{0}\right)+e_{p 0}} .
$$

Using equation (4), the average effective prestress of $\mathrm{P} / \mathrm{S}$ strands in the tensile region can be determined by

$$
\sigma_{p 0}=\frac{N_{p 0}}{A_{y}}=\frac{M_{c r}}{A_{y}\left(\left(I_{0} / A_{0} \cdot y_{0}\right)+e_{p 0}\right)} .
$$

And the average effective strain of $\mathrm{P} / \mathrm{S}$ strands in the tensile region can be calculated by

$$
\varepsilon_{p 0}=\frac{N_{p 0}}{E_{y} A_{y}}=\frac{M_{c r}}{E_{y} A_{y}\left(\left(I_{0} / A_{0} \cdot y_{0}\right)+e_{p 0}\right)} .
$$

2.2. Principle for Effective Prestress Determination by the Posttensioning Method. Similarly, for posttensioned flexural members, we have

$$
\begin{aligned}
\sigma_{p c} & =\frac{N_{p 0}}{A_{n}}+\frac{N_{p 0} \cdot e_{p n}}{\omega_{n}}=\frac{N_{p 0}}{A_{n}}+\frac{N_{p 0} \cdot e_{p n}}{I_{n}} \cdot y_{n} \text { including } \omega_{n} \\
& =\frac{I_{n}}{y_{n}},
\end{aligned}
$$

$M_{c r}=\left(\sigma_{p c}+\gamma \cdot f_{t k}\right) \frac{I_{0}}{y_{n}}$.

For cracked structures, the cracked concrete in the tensile region cannot resist any tensile strain, i.e., $\varepsilon_{t k}=0$ and $f_{t k}=0$; then, equation (8) can be rewritten as

$$
\begin{aligned}
M_{c r} & =\sigma_{p c} \cdot \frac{I_{0}}{y_{n}}=\left(\frac{N_{p 0}}{A_{n}}+\frac{N_{p 0} \cdot e_{p n}}{I_{n}} \cdot y_{n}\right) \cdot \frac{I_{0}}{y_{n}} \\
& =N_{p 0}\left(\frac{I_{0}}{A_{n} \cdot y_{n}}+e_{p n}\right) .
\end{aligned}
$$

Based on equation (9) and considering the critical redecompression state, the effective prestress of $\mathrm{P} / \mathrm{S}$ strands in the tensile region is given by

$$
N_{p 0}=\frac{M_{c r}}{\left(I_{0} / A_{n} \cdot y_{n}\right)+e_{p n}} .
$$

Using equation (10), the average effective prestress of $\mathrm{P} / \mathrm{S}$ strands in the tensile region is determined by 


$$
\sigma_{p 0}=\frac{N_{p 0}}{A_{y}}=\frac{M_{c r}}{A_{y}\left(\left(I_{0} / A_{n} \cdot y_{n}\right)+e_{p n}\right)} .
$$

\section{Effective Prestress Analysis Based on the Critical Decompression Moment Test for PC Beams with Breathing Cracks}

The decompression moment is proposed by Indian scholar Ramaswamy [33]: the virtual external moment when the prepressing stress of the outermost concrete in the tensile zone is offset to zero. For statically determinate structures, when the internal force of the test section reaches the critical decompression state, the sum of the moment under the dead load and test load is the decompression moment of the section. Then, the effective prestressing force of the strand in tensile zone can be calculated by equations (4) and (10), respectively. To verify the accuracy and consistency of the analysis principle and calculation model above, a test of 6 model concrete beams with the typical size of $800 \mathrm{~cm}$ (length) $\times 30 \mathrm{~cm}$ (width) $\times 50 \mathrm{~cm}$ (height) and C50 strength was conducted. The P/S strands are the high strength, low relaxation strands. The nominal diameter is $15.24 \mathrm{~mm}$. The test first adopts the single-point loading method to test beam's mid-span section with the loading up to the cracking state. Under the single-point loading, the first major crack and subsequent cracks occur around the embedded sensor at the mid-span section of main beam or in the rebars near the beam ends (Model JMZX-416AT, sensor length $\approx 20 \mathrm{~cm}$, strand $\approx 30 \mathrm{~cm}$ long connected to the rebar on the lowest edge of the main beam with butt welding). After the completion of loading, unload to zero, put the main beam on the flat ground, and retract the anchorage device of strands simultaneously. Stretch the strands of test beam again by the design test scheme after recovering the residual deformation of test beam for $24 \mathrm{~h}$, conduct the graded loading ( 23 steps totally are listed in Table 1) on the beam again, and record the strains, deflections, and cracks of controlling section at each load level. For the loading mode, load step by step by Jack during the test process, and put the proving ring between Jack and reaction frame to control the test load. The test setup and the location of the instrument in the mid-span section are shown in Figures 2-4, respectively.

3.1. Test Parameters. To avoid the influence of the material dispersion and construction technology between different samples on the test law, the voids of the samples were not grouted during the test. Only the tensile control stress was changed in each set of tests. Then, the test results were compared and analyzed under different tensile stress control conditions. The load gradation and control parameters of test beams are listed in Table 1.

3.2. Test Method. In this paper, the stress increment of the cross-crack steel bars with closed cracked section is used in the tensile zone. In order to ensure the reliability of the test results and ensure that the first crack crosses the embedded rebar meter sensor in the middle of the span (sensor types: JMZX-416AT, the sensor length is about $20 \mathrm{~cm}$. There are about $30 \mathrm{~cm}$ connecting rebars at both ends. But welding is used to tie both ends of the rebar with the rebar at the bottom edge of the main beam), the single point loading of the midspan section is adopted in this test. The loading method is shown in Figure 2. And the test load and loading steps are shown in Table 1.

The model beam in this paper is a simply supported beam. When the mid-span section is loaded at a single point, the internal force of the $L / 2$ section under both constant load and test load is the maximum. The first vertical crack and the main crack in the mid-span section appear directly below the Jack in the mid-span section. This crack appears first, develops fastest, and owns the highest height and the widest width (as shown in Figure 5). And there are several small cracks in the cross-sections far away from the mid-span. Under the action of the same level of load, the farther the distance from the mid-span section, the later the crack appears, the shorter the length, and the smaller the width. Since the core part of the rebar meter sensor embedded in the mid-span is about $20 \mathrm{~cm}$, the first crack and the main crack are basically under the Jack of the mid-span section, ensuring that the crack can cross the steel bar meter sensor in the tensile zone of the mid-span.

3.3. Test Results and Analysis. According to the above test methods, the traditional stress increment-load curves were analyzed, as shown in Figure 6. The stress variation rate versus load curves obtained by the proposed method [34] are shown in Figure 7; the evaluation errors of the effective prestresses calculated according to Reference [20] are shown in Table 2.

As indicated in Figures 6 and 7 and Table 2,

(1) The traditional test analysis method is not sensitive to the stress change of the cracked section in the tension zone under the critical decompression state, while the test load and stress change rate method proposed in this study can definitively determine the critical decompression state with closed fracture sections.

(2) The error between the experimental load and the theoretical load predicted by the proposed method is larger than that predicted by the effective prestressing force. This is mainly because the total bending moment of the section caused by the effective prestressing force includes the constant and test loads. At the same time, it also shows that the test load is more sensitive to the assessment of the effective prestress of the section than the total compression dissipation moment of the section.

(3) According to the improved stress-relieving moment test results proposed in this study, the calculated effective prestress is close to the theoretical calculation result with the maximum error less than $7 \%$ which is practically acceptable. The proposed method gives more reasonable prediction than the 
TABLE 1: Summary of the investigated system parameters.

\begin{tabular}{|c|c|c|c|c|c|c|}
\hline Specimen & $\begin{array}{c}\text { Strength characteristics } \\
\text { of strands }\end{array}$ & $\begin{array}{c}\text { Tension-control stress of } \\
\text { strands }(\mathrm{MPa})\end{array}$ & $\begin{array}{l}\text { Average effective tensile } \\
\text { stress of strands }(\mathrm{MPa})\end{array}$ & $\mathrm{DM}(\mathrm{N} \cdot \mathrm{mm})$ & $\begin{array}{l}\text { Load } \\
\text { series }\end{array}$ & $\begin{array}{l}\text { Maximum test } \\
\text { load, } \mathrm{kN}\end{array}$ \\
\hline \multirow{2}{*}{$\# 1$} & $N_{p 0}$ & 818.4 & 786.16 & 81917919.7 & \multirow{3}{*}{23} & \multirow{3}{*}{90} \\
\hline & $1.25 N_{p 0}$ & 1023 & 980.67 & 102186849.3 & & \\
\hline$\# 2$ & $1.7 N_{p 0}$ & 1395 & 1323.79 & 137939661.7 & & \\
\hline
\end{tabular}

Single-end tension was used during the test. The load sequences at the middle section are 5, 10, 15, 20, 25, 30, 35, 40, 45, 50, 55, 60, 62.5, 57.5, 65, 70, 80, 75, $77.5,72.5,82.5,85$, and 90 (unit: $\mathrm{kN}$ ). The effective prestress calculation method and parameters are taken from the Chinese code "Specifications for design of highway reinforced concrete and prestressed concrete bridges and culverts."

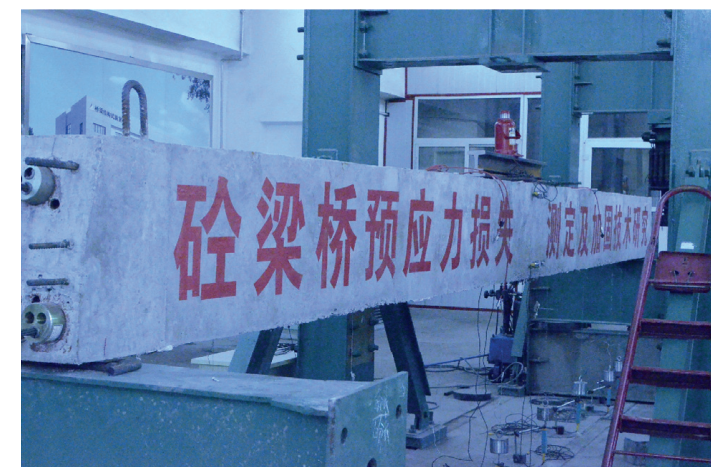

Figure 2: Data acquisition and loading test.
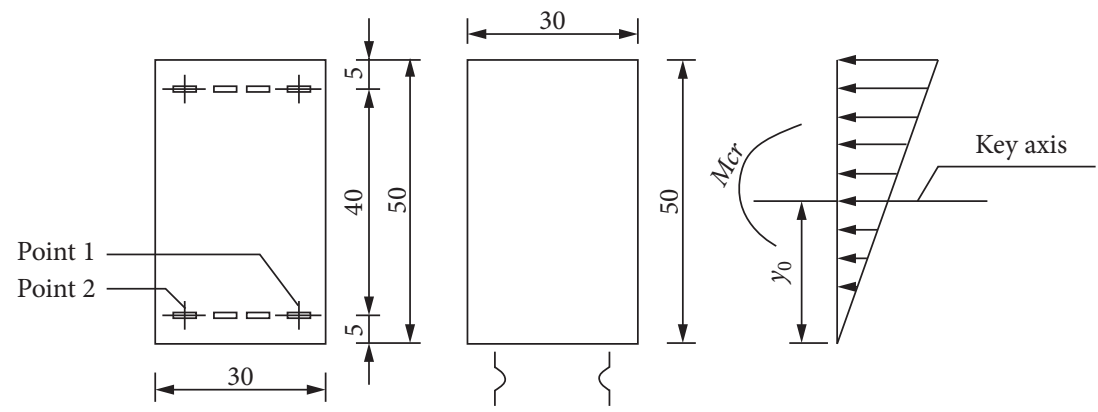

1. is the measurement point location of steel strain gauge

2. $\square$ is the measurement point location of concrete strain gauge

3. $\_$is the measurement point location of bottom strain gauge

FIGURE 3: Instrument installation at the mid-span section of test beam.

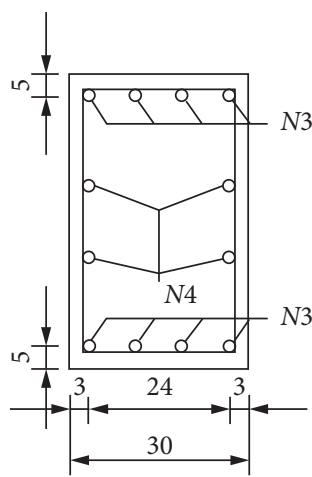

(a)

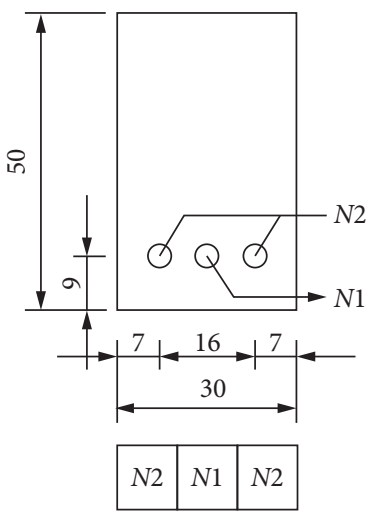

(b)

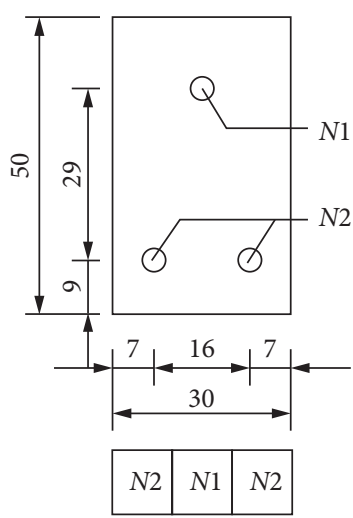

(c)

Figure 4: Position of steel bars and strands. (a) Steel bars. (b) Strand (L/2). (c) Strand (anchor end). 


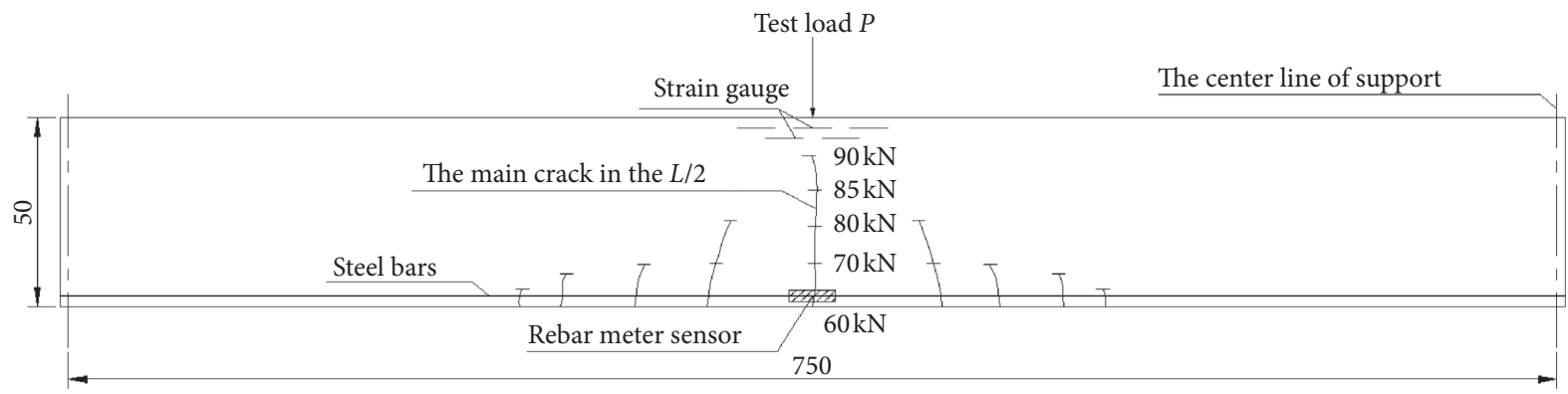

FIgURE 5: Schematic diagram of the crack development of $\# 1$ specimen at $1.25 N_{\mathrm{p} 0}$ (unit: $\mathrm{cm}$ ).

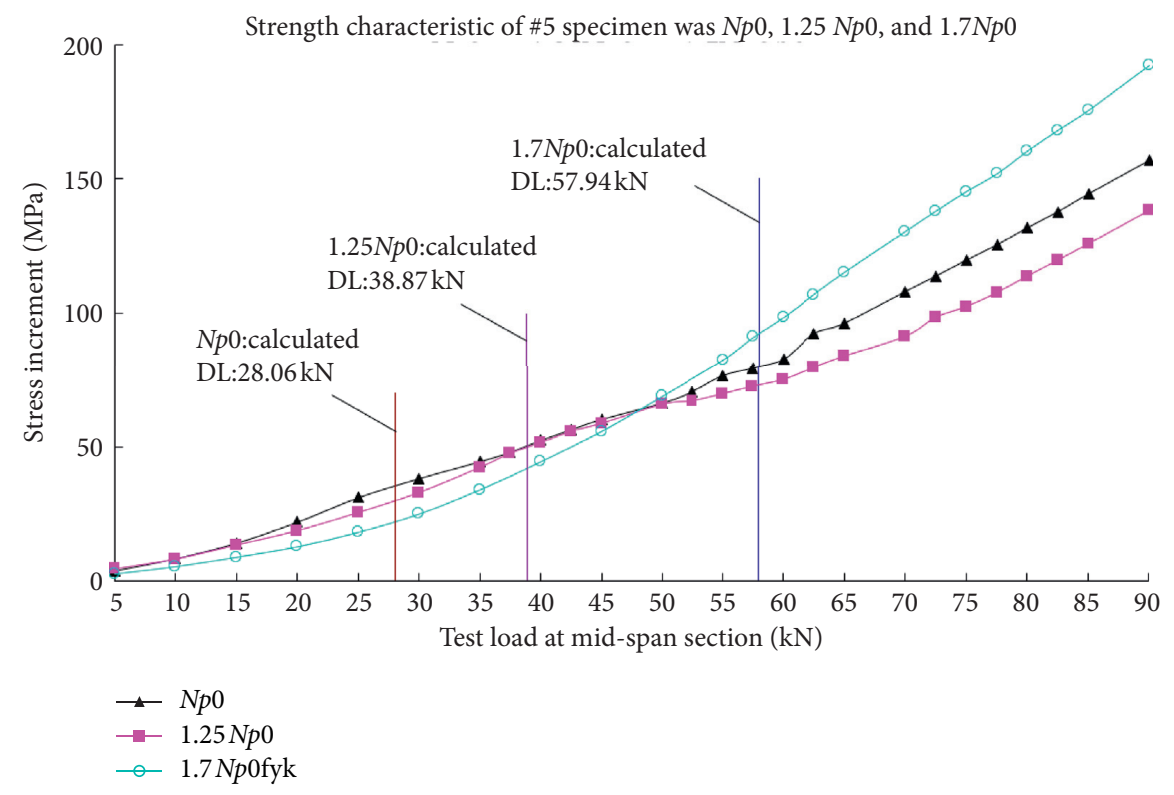

Figure 6: Stress increment vs. load curve by the traditional method (by test data).

Strength characteristic of $\# 5$ specimen was $N p 0,1.25 N p 0$, and $1.7 N p 0$

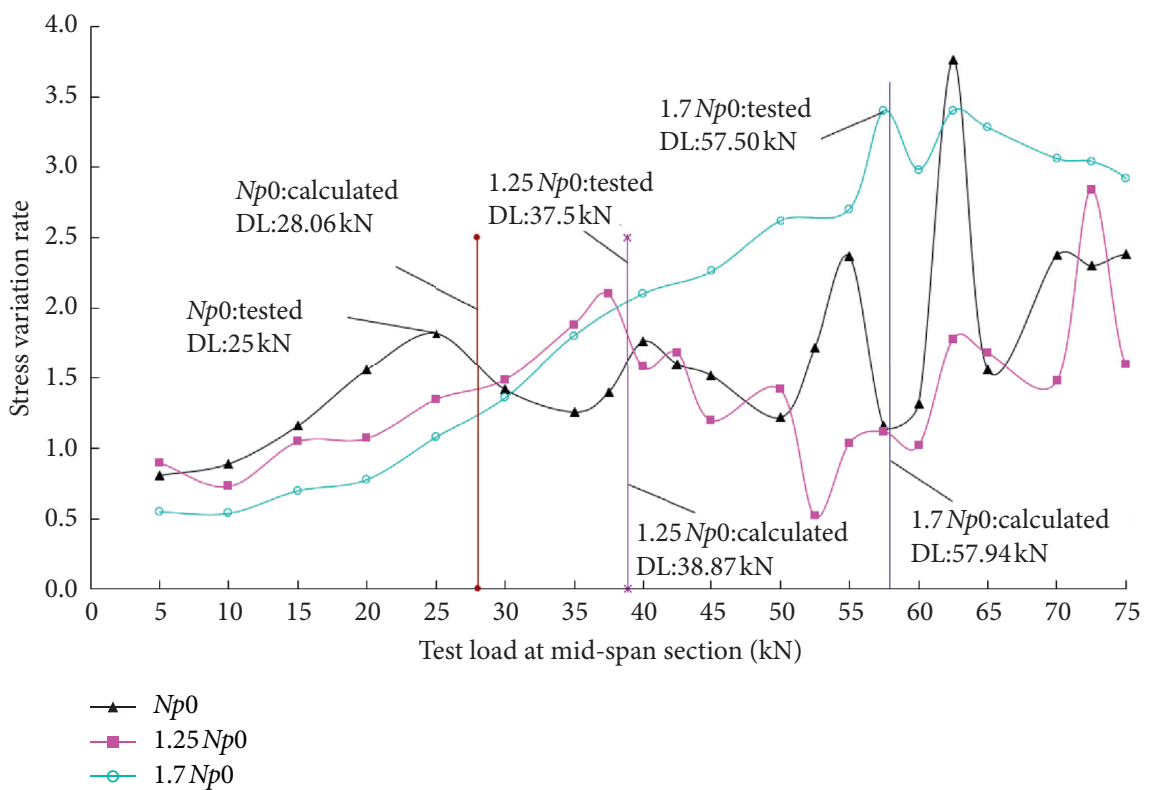

FiguRe 7: Stress variation rate vs. load curve by the proposed method (by test data). 
TABLE 2: Error analysis of the calculated results with different strength characteristics.

\begin{tabular}{lccccccccc}
\hline Specimen & $\begin{array}{c}\text { Strength } \\
\text { characteristics of } \\
\text { strand }\end{array}$ & $\begin{array}{c}M_{g} \times 10^{7} \\
(\mathrm{~N} \mathrm{~mm})\end{array}$ & $\begin{array}{c}P_{\text {test }} \times 10^{4} \\
(\mathrm{~N})\end{array}$ & $\begin{array}{c}D M_{\text {test }} \times 10^{7} \\
(\mathrm{~N} \mathrm{~mm})\end{array}$ & $\begin{array}{c}P_{\text {theory }} \times 10^{4} \\
(\mathrm{~N})\end{array}$ & $\begin{array}{c}\text { Error } \\
(\%)\end{array}$ & $\begin{array}{c}\sigma_{p 0 \text { theory }} \\
(\mathrm{MPa})\end{array}$ & $\begin{array}{c}\sigma_{p 0 \text { test }} \\
(\mathrm{MPa})\end{array}$ & $\begin{array}{c}\text { Error } \\
(\%)\end{array}$ \\
\hline$\# 1$ & $N_{p 0}$ & 4.62 & 2.50 & 7.62 & 2.81 & -10.9 & 786.16 & 731.01 & -7.0 \\
$\# 2$ & $1.25 N_{p 0}$ & 4.62 & 3.75 & 9.96 & 3.89 & -3.5 & 980.67 & 955.94 & -2.5 \\
& $1.7 N_{p 0}$ & 4.62 & 5.75 & 1.37 & 5.79 & -0.8 & 1323.79 & 1315.82 & -0.6 \\
\hline
\end{tabular}

$\mathrm{Mg}$ is the mid-span moment of the test beam under a constant load. The weight of the test device and Jack is about $1 \mathrm{kN}$. $N_{p 0}$ is the tensile force of each strand $=114.576 \mathrm{kN}$. $P_{\text {test }}$ and $P_{\text {theory }}$ are, respectively, the theoretical and experimental vertical loads at the mid-span of the test beam.

previous empirical method based on crack width and mid-span deflection.

(4) It can be seen from Figure 6 that when the prestressing force of \#1 specimen is increased from $N_{p 0}$ to $1.25 N_{P 0}$, the stress increment at the same measuring point of $\mathrm{L} / 2$ section also decreases on the whole [28]. It is consistent with the experimental results in reference [28]. However, because the crack morphology and damage degree of the L/2 section about \#2 specimen are not completely consistent with \#1 specimen, the change rule of stress increment of \#2 specimen is somewhat different from \#1 specimen. But it does not affect the judgment result of the critical decompression state of each beam under different prestressing force conditions.

\section{Numerical Analysis on the Critical Decompression State of Closed Crack Sections Based on Fracture Mechanics}

The vertical crack near the mid-span of the main beam is a typical Type I crack in fracture mechanics. When the internal force state with a closed cracked section does not reach the critical decompression state, the height of the compression zone is the height of the full section. If the analysis is carried out according to the converted section method based on the assumption of the plane section in literature [20], the section properties are the same as that of the uncracked section, and the difference of the influence of the closed crack on the stress field of the section cannot be considered.

4.1. Model Beam Information. In order to understand the crack development and the stress variation of the section near cracks during the process of crack closing to crack reopening, the extended finite element method (XFEM) [21-24] based on Abaqus program [35] was used to simulate cracked sections.

4.1.1. Section and Material. The material, structural size, position of reinforcement and strand, and the effective prestress of the strand in the mid-span section of the simulated beam are identical to those of the test beam described in Section 3.
4.1.2. Boundary Conditions. One end of the test beam is provided with hinged support at $250 \mathrm{~mm}$ from the end; the other end is provided with only the vertical support.

4.1.3. Effective Prestress. The effective prestress in the strands was calculated using Midas program [36].

4.1.4. Load Application and Meshing. Because the simulated object is a SS beam, the distribution of internal forces and the stress state of the section are only related to the magnitude of load; and the position of section, the development state of material and cracking, the similarity of internal forces, and deformations of other sections cannot be taken into account in the calculation. The magnitude of the load in mid-span: in order to avoid the abnormal local stress, the vertical load is adopted; the action area is $300 \mathrm{~mm} \times 500 \mathrm{~mm}$, and the concentrated load is equivalent to the total force of the loading stages, consistent with those in Table 1.

Element discretization: solid elements for the concrete in the main beam spaced at $500 \mathrm{~mm}$ longitudinally (reduced to $10 \mathrm{~mm}$ within the middle $500 \mathrm{~mm}$ ), $10 \mathrm{~mm}$ vertically, and $75 \mathrm{~mm}$ transversely; and truss elements for rebars and P/S strands (element length $=5 \mathrm{~mm}$ ). The discretized finite element model is shown in Figure 8.

4.2. Calculation Parameters and Closed Crack Simulation Method. In order to simulate the actual situation that the concrete cannot bear the tensile strain at the closed crack in the middle section of the main beam, the prefabricated (known position) crack analysis method of XFEM [30-34] was adopted in this study, and the crack position was set on the lower edge of mid-span. Considering that the concrete material at the crack can bear pressure but cannot bear the tensile strain, theoretically, the maximum principal tensile stress of the material should be strictly set at $0 \mathrm{MPa}$. At the same time, according to the literature [37], the fracture energy $G_{F}$ of concrete material in the initial cracking state is $G_{F}=\int \sigma \mathrm{d} w$, where $\sigma$ is the tensile stress in the fracture zone of the cracking section and $w$ is the corresponding deformation with $\sigma$, indicating that the fracture energy is proportional to the tensile stress of the material. However, because the concrete material with closed crack cannot bear tensile stress, its fracture energy in a strict sense should also be set as $0 \mathrm{~N} / \mathrm{mm}$. On the other hand, considering the discreteness of the concrete material itself and the convergence of the calculation software ABAQUS, in order to be 


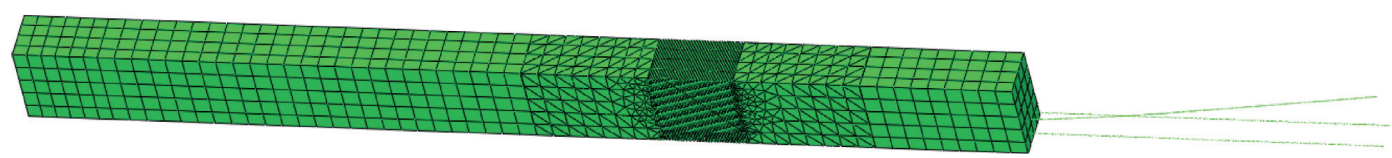

FIGURE 8: Discretization of the finite element model.

close to the actual stress state of the model test beam in Section 3, this paper refers to the actual mechanical property parameters of the concrete material (the standard axial tensile strength of C50 concrete is $2.65 \mathrm{MPa}$ [20], and the measured fracture of C40 concrete can be more than $0.12 \mathrm{~N} /$ $\mathrm{mm}$ [37]). Considering the law that the fracture energy of concrete is proportional to the strength, it is assumed that the maximum principal tensile stress of concrete is $0.01 \mathrm{MPa}$ and the fracture energy is $0.01 \mathrm{~N} / \mathrm{mm}$ (which are two or one order of magnitude smaller than the test results of normal materials) in this simulation with closed cracks. If the fracture energy is modified to $0.001 \mathrm{~N} / \mathrm{mm}$, the calculation results of the model can still converge without affecting the judgment results of the critical pressure extinction state. Only in this way, we can simulate the reality that the concrete fiber with closed crack cannot bear the tensile strain. The specific calculation parameters are listed in Table 3.

4.3. Calculation Results of Concrete Stress at the Lower Edge of the Cracked Section. The strain calculation results of the concrete and steel bars at the lower edge of the section with closed cracks in the mid-span tested in Section 3 are shown in Figures 9-11. Figure 11 shows the numerical analysis results of concrete stress within the range of the mid-span section with closed cracks (longitudinal bridge direction $1 \mathrm{~cm}$, the full height of the beam $50 \mathrm{~cm}$ ) of the model test beam in Section 3. In order to more clearly show the re-opening of the crack in the main beam with a closed crack element under the critical decompression state, the first two columns in Figure 11 present the concrete stress distribution within the full height range of the main beam, while the third column only shows the development of the crack at the lowest edge of the beam element.

As shown in Figures 9-11 and Table 4,

(1) As we can be seen from Figures 9 and 10, the slope change at the abrupt transition point of the test loadstress change rate curve of rebars in the tensile zone is more obvious than the test load-stress increment curve of rebars in the tensile zone before and after the internal force of the test section reaches the critical decompression state. And the former mutation point is easier to be determined. The results are consistent with the experimental analysis in Section 3.

(2) According to the stress analysis results of the rebars in the tensile zone shown in Figure 10, when the tension control force is $N_{p 0}, 1.25 N_{p 0}$, and $1.7 N_{P 0}$, respectively, the mid-span section basically reaches the critical decompression state when the load of the mid-span section is $22.06 \mathrm{kN}, 38.87 \mathrm{kN}$, and
$57.94 \mathrm{kN}$, respectively. It is shown that the numerical analysis results are consistent with the theoretical calculation in Section 3 when the test load-stress change rate of the rebar in the tensile zone curve method proposed in this paper is used to determine the critical decompression state of the section.

(3) According to the analysis results of stress distribution of concrete in the tensile zone shown in Figure 11 and Table 4, the test DMs predicted by the proposed method are basically consistent with the numerical analysis results. When the simulated load at the mid-span is increased to the critical DM load, the maximum tensile stress of the bottom concrete edge is found to be less than $0.04 \mathrm{MPa}$, which is basically in the critical decompression state. The maximum error of the judgment result of critical decompression moment based on the rate of stress change of rebars in the tensile zone is not more than $0.7 \%$ compared with that of the judgment result based on the outermost stress distribution. The numerical analysis results of the critical decompression state of concrete in the tensile zone with a closed cracked section based on the fracture mechanics principle are basically consistent with the determination results based on the test loadstress change rate curve of the rebar in the tensile zone and the test results in the Section 3. It is shown that the analysis method based on the test loadstress change rate curve of the rebar in the tensile zone can meet the requirements of engineering accuracy.

(4) According to the test results in Figure 4 and the numerical analysis results in Figures 7 and 10, the assumption about the crack initiation parameters of a closed cracked section in this paper can basically simulate the mechanical performance of the closed cracked cross-section material that can bear pressure but cannot bear the tension. The numerical simulation analysis results are basically consistent with the test results.

\section{Analysis and Discussion of Test Results}

The phenomenon of closed cracks is a common thing in existing PC bridges. Concerning the various sensitivity of different parameters during the test process and numerical analysis, the nonlinearity of the prestressed concrete section with closed cracks in the critical cracking state, and the reasonable selection of a calculation method for effective prestressing force, a further in-depth discussion is presented as follows. 
TABLE 3: Material calculation parameters.

\begin{tabular}{lcccccc}
\hline $\begin{array}{l}\text { Material } \\
\text { name }\end{array}$ & $\begin{array}{c}\text { Density } \\
\left(\mathrm{T} / \mathrm{mm}^{3}\right)\end{array}$ & $\begin{array}{c}\text { Modulus of } \\
\text { elasticity }(\mathrm{MPa})\end{array}$ & $\begin{array}{c}\text { Poisson's } \\
\text { ratio }\end{array}$ & $\begin{array}{c}\text { Average effective tensile } \\
\text { stress of strands }(\mathrm{MPa})\end{array}$ & $\begin{array}{c}\text { Assumed maximum } \\
\text { principal stress }(\mathrm{MPa})\end{array}$ & $\begin{array}{c}\text { Assumed fracture } \\
\text { energy }(\mathrm{N} / \mathrm{mm})\end{array}$ \\
\hline $\begin{array}{l}\text { C50 } \\
\text { concrete }\end{array}$ & $2.6 \times 10^{-9}$ & $3.45 \times 10^{4}$ & 0.2 & & 0.01 & 0.01 \\
$\begin{array}{l}\text { Steel } \\
7.85 \times 10^{-9}\end{array}$ & $2.0 \times 10^{5}$ & 0.3 & & - & - \\
Strand & $7.85 \times 10^{-9}$ & $1.95 \times 10^{5}$ & 0.3 & $\begin{array}{c}\mathrm{Np} 0: 786.16 \mathrm{MPa} \\
1.25 \mathrm{~Np} 0: 980.67 \mathrm{MPa} \\
1.7 \mathrm{~Np} 0: 1323.79 \mathrm{MPa}\end{array}$ & - & - \\
\hline
\end{tabular}

The load series at the middle section is $5,10,15,20,25,30,35,40,45,50,55,60,62.5,57.5,65,70,80,75,77.5,72.5,82.5,85$, and 90 (unit: $\mathrm{kN}$ ); and the computing moment $\Delta M_{L / 2}=\Delta P \times L_{j} / 4$ (unit: $\mathrm{N} \cdot \mathrm{mm}$ ). Average effective tensile stress of strand reference from Table 1 .

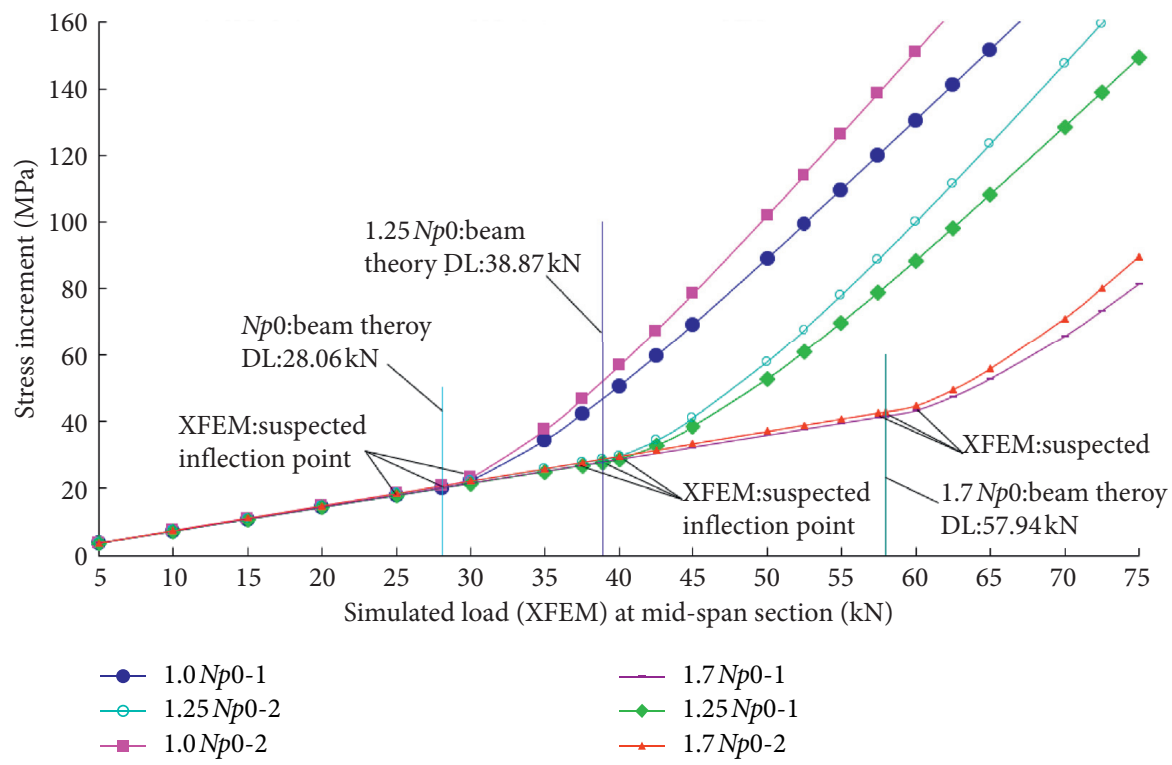

FIGURE 9: Stress increment vs. load curves by the traditional method (rebar data).

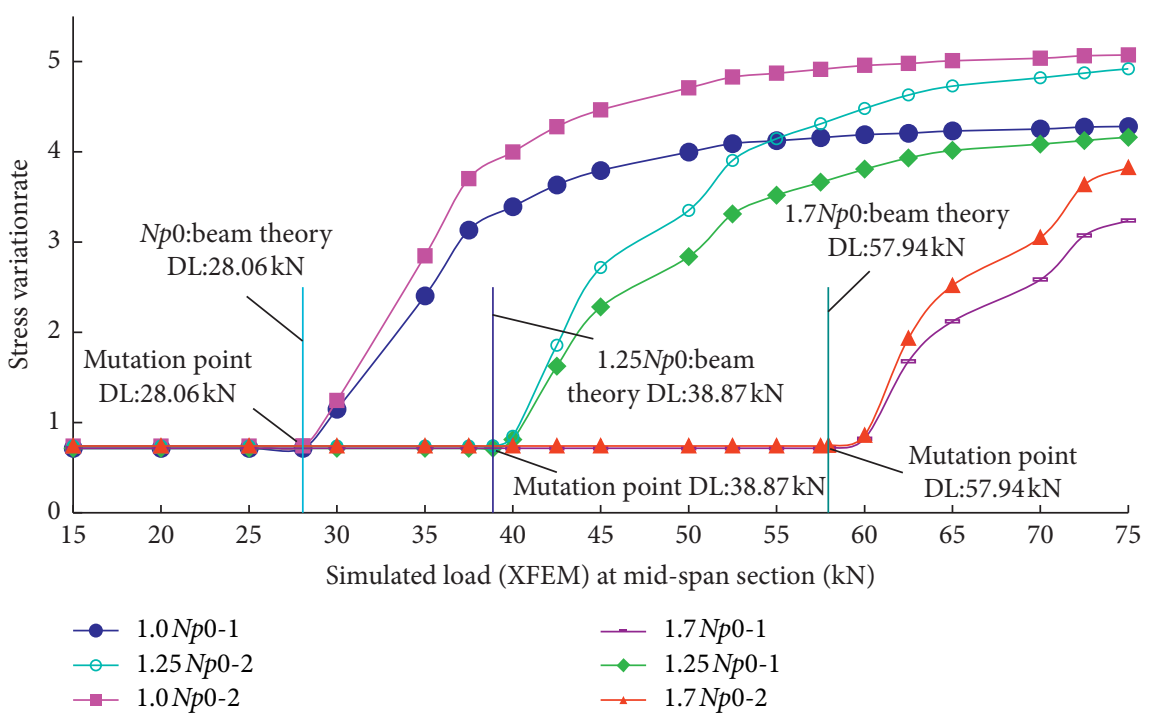

Figure 10: Stress variation rate vs. load curves by the proposed method (rebar data). 


\begin{tabular}{|c|c|c|}
\hline 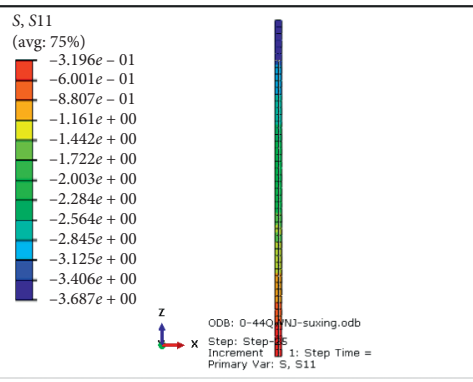 & 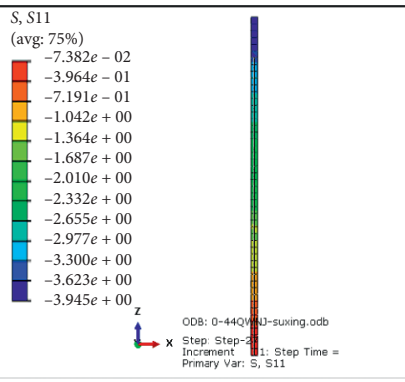 & 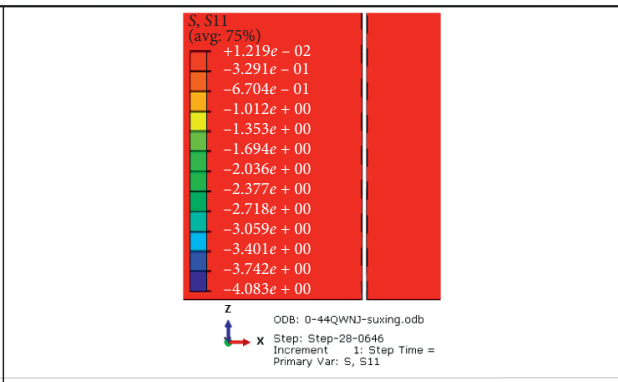 \\
\hline $\begin{array}{l}N p 0: P=25 \mathrm{kN} \text {, full section compression, } \\
\text { crack closure (the abrupt load level of } \\
\text { the test curve is shown in fig.5); }\end{array}$ & $\begin{array}{l}N p 0: P=27 \mathrm{kN}, \text { full section } \\
\text { compression, crack closure; }\end{array}$ & $\begin{array}{c}N p 0: P=28.06 \mathrm{kN} \text {, tensile stress that appeared at the } \\
\text { lower edge is } 0.012 \mathrm{Mpa} \text {, and the crack began to } \\
\text { open. }\end{array}$ \\
\hline 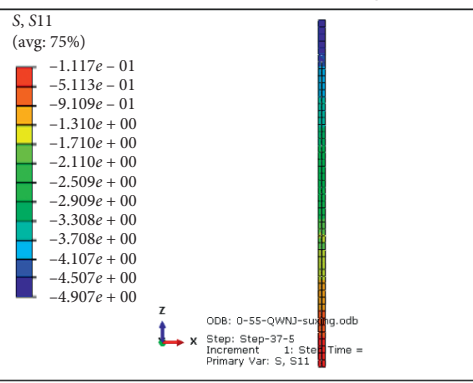 & 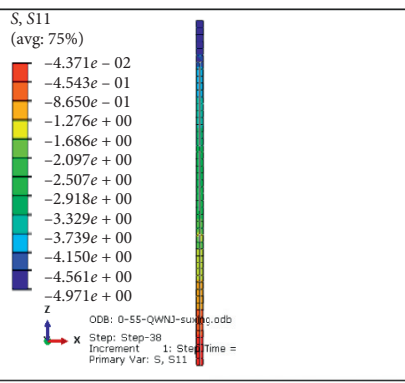 & 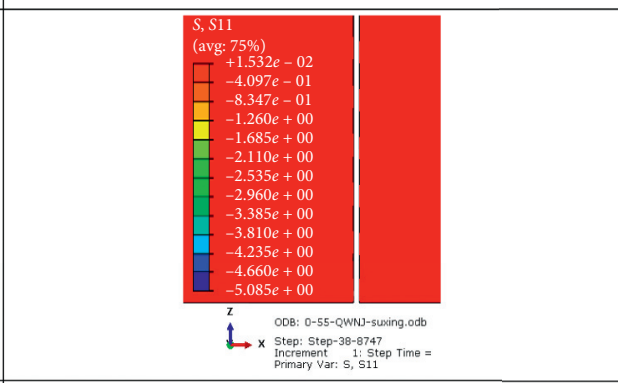 \\
\hline $\begin{array}{c}1.25 N p 0: P=37.5 \mathrm{kN} \text {, full section } \\
\text { compression, crack closure (The abrupt } \\
\text { load level of the test curveis shown in } \\
\text { Fig. } 5 \text { ); }\end{array}$ & $\begin{array}{l}1.25 N p 0: P=38 \mathrm{kN} \text {, full section } \\
\text { compression, crack closure; }\end{array}$ & $\begin{array}{c}N p 0: P=38.87 \mathrm{kN} \text {, tensile that appeared appeared at the } \\
\text { lower edge is } 0.015 \mathrm{Mpa} \text {, and the crack began to } \\
\text { open. }\end{array}$ \\
\hline 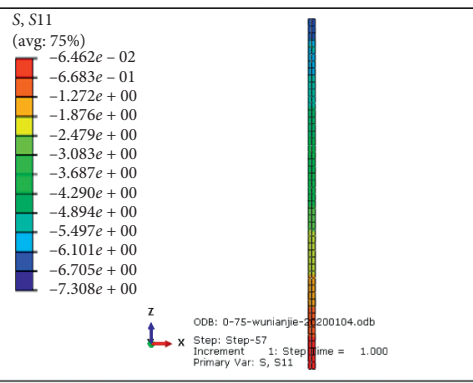 & 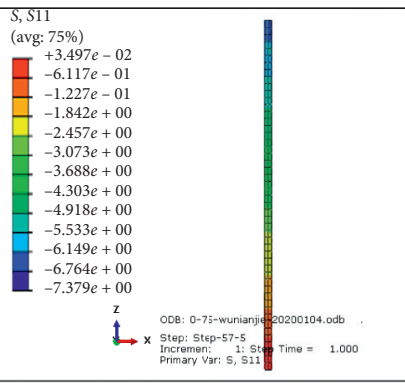 & 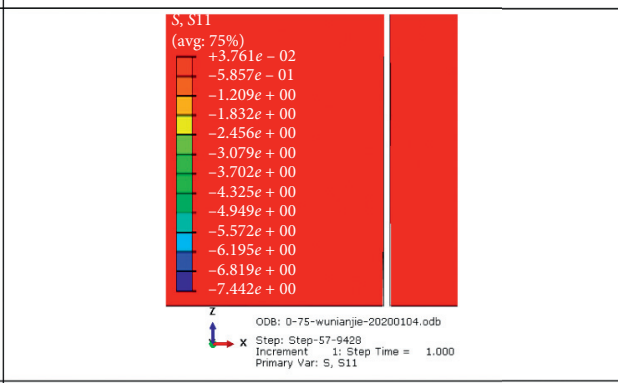 \\
\hline $\begin{array}{l}1.7 N p 0: P=57 \mathrm{kN} \text {, full section } \\
\text { compression, crack closure; }\end{array}$ & $\begin{array}{c}1.7 N p 0: P=57.5 \mathrm{kN} \text {, tensile stress } \\
\text { appeared in the lower edge is } \\
0.035 \mathrm{Mpa} \text {, but the crack did not } \\
\text { open obviously (the abrupt load } \\
\text { level of the test curve is shown in } \\
\text { Fig. 5); }\end{array}$ & $\begin{array}{c}1.7 N p 0: P=57.94 \mathrm{kN} \text {, tensile that appeared at } \\
\text { the lower edge is } 0.038 \mathrm{Mpa} \text {, and the crack } \\
\text { began to open. }\end{array}$ \\
\hline
\end{tabular}

FIGURE 11: Stress and crack variation trends of the closed cracked concrete section (by XFEM).

TABLE 4: Error analysis on the results with different strength characteristics (XFEM).

\begin{tabular}{|c|c|c|c|c|c|c|c|c|c|}
\hline \multirow{2}{*}{$\begin{array}{l}\text { Strength } \\
\text { characteristics of } \\
\text { strands }\end{array}$} & \multicolumn{3}{|c|}{$\begin{array}{l}P \text { (by stress change of rebars in the } \\
\text { tension zone, as shown in Figure 10) }\end{array}$} & \multicolumn{3}{|c|}{$\begin{array}{c}P \text { (by concrete strain distribution, as } \\
\text { shown in Figure } 11)\end{array}$} & \multicolumn{3}{|c|}{$\sigma_{p 0}$} \\
\hline & $\begin{array}{c}P_{\text {theory }} \times 10^{4} \\
(\mathrm{~N})\end{array}$ & $\begin{array}{l}P_{\mathrm{XFEM}} \times 10^{4} \\
(\mathrm{~N})\end{array}$ & $\begin{array}{c}\text { Error } \\
(\%)\end{array}$ & $\begin{array}{l}P_{\text {theory }} \times 10^{4} \\
(\mathrm{~N})\end{array}$ & $\begin{array}{l}P_{\text {XFEM }} \times 10^{4} \\
(\mathrm{~N})\end{array}$ & $\begin{array}{c}\text { Error } \\
(\%)\end{array}$ & $\begin{array}{c}\sigma_{\text {p0XFEM }} \\
(\mathrm{MPa})\end{array}$ & $\begin{array}{l}\sigma_{p 0 \text { test }} \\
(\mathrm{MPa})\end{array}$ & $\begin{array}{c}\text { Error } \\
(\%)\end{array}$ \\
\hline$N_{p 0}$ & 2.81 & 2.81 & 0 & 2.81 & 2.81 & 0 & 786.16 & 731.01 & -7.0 \\
\hline $1.25 N_{p 0}$ & 3.89 & 3.89 & 0 & 3.89 & 3.89 & 0 & 980.67 & 955.94 & -2.5 \\
\hline $1.7 N_{p 0}$ & 5.79 & 5.79 & 0 & 5.79 & 5.75 & -0.7 & 1323.79 & 1315.82 & -0.6 \\
\hline
\end{tabular}

$P_{\text {theory }}$ and $P_{\text {test }}$ are, respectively, the theoretical and simulated vertical loads at the mid-span of the test beams.

5.1. Reliability Analysis of the Proposed Test Method. The experimental results in Figure 5 and the numerical simulation results in Figures 8 and 9 show that the critical DM state of the section with breathing cracks can be accurately determined by improving the sensitivity of target parameters to the variation of section characteristics. The curve features and results between the numerical simulation and test are identical. Moreover, the analysis results in Tables 2 and 4 
indicate that the effective prestressing force of the test section can be derived by the proposed test method, as validated by the numerical results.

On the other hand, it can be seen from the comparative analysis results of Figures 4 and 5, as well as Figures 7 and 8, that the curve slope change at the inflection point of Figures 5 and 8 is more than double that of Figures 4 and 7. This is mainly because Figures 5 and 8 adopt the stress variation rate-load curves of reinforcements in the tensile zone by the proposed method. In other words, they represent the changing law of slope of the curves in Figures 4 and 7. Obviously, the trend of the slope of a curve is more sensitive than the curve itself, making the inflection point easier to identify.

\subsection{Nonlinearity Analysis of Mechanical Properties of Cracked} Damaged Sections. Concrete is a quasi-brittle material. It is a reasonable method to deduce the critical decompression moment and effective prestressing force of the test section through the critical decompression state test with a closed fracture section. Because the concrete in the tensile zone of the closed crack section cannot bear the tensile strain, but it can bear the compressive strain, therefore, whether the damage caused by the closed crack has an influence on the critical decompression state is the key problem for the accurate determination of the critical decompression state. On the other hand, the results of references $[38,39]$ show that the concrete in the tensile zone under critical cracking state displays the material nonlinearity effect, resulting in a greater measured cracking moment than the theoretical value. However, for a prestressed concrete section with closed cracks, the issues of re-cracking and re-cracking moment have not been fully addressed yet.

The test results from this study show that the critical recracking moment of the section with closed cracks at the mid-span is essentially consistent with the theoretically calculated decompression moment; the linear relationship of stress change rate between the measured bending moment and the rebars in the tensile zone is generally good; and there is no obvious nonlinear effect. The main reasons are as follows: the whole section is in a compression state before the prestressed concrete section with closed cracks is close to the decompression, the whole concrete section is not really subjected to tensile strain, and the effect of tensile strain-softening of concrete material has not occurred yet. At the same time, the stress level of the concrete section is relatively low in the critical decompression state, and the material properties are essentially within the elastic range. Therefore, according to the linear superposition principle, that is, the critical recracking moment of the prestressed concrete section with closed cracks is equal to its decompression moment, there is no need to consider the impact of nonlinear factors such as the plastic moment resistance effect of the plain concrete section on a critical re-cracking moment, which is the theoretical basis for calculating the total prestressing force in the tensile zone for a prestressed concrete section with closed cracks.
5.3. Rational Calculation Method for Prestressing Forces. According to the literature of [20], there are two main calculation methods for the correlation between prestressing force and decompression or cracking moment: (1) elastic analysis method of $T_{p}=\left(M_{c r}-T_{s}\left(h_{s}-x / 3\right) /\left(h_{p}-x / 3\right)\right)$ for cracked sections, where $x$ is the height of compression zone of concrete section, $T_{s}$ is the resultant force of the tension of the rebars in the tensile zone, $T_{p}$ is the actual tensile force of the P/S strand in the tensile zone, $H_{s}$ is the distance between the center of resultant force point of the rebars in the tensile zone and the edge of compression zone, and $H_{p}$ is the distance between the center of resultant force point of the strands in the tensile zone and the edge of compression zone; (2) elastic analysis method for the whole section under the compression of $N_{p 0}=\left(M_{c r} /\left(I_{n} / A_{n} \cdot y_{n}\right)\right.$ $\left.+e_{p n}\right)$. The shrinkage and creep effect will occur in the concrete material under long-term load. However, there are no shrinkage and creep phenomena in steel, thus resulting in a deformation difference [38] and nonzero stress in the rebars under the decompression state of concrete, which causes difficulties in calculating the prestressing force. So it would be unwise to deduce the effective prestressing force by method (1). And the calculation method (2) is shown in equations (4) and (10).

5.4. Rational Selection of Calculation Parameters. For the concrete section with closed cracks, it is also a question worthy of further consideration whether the damage effect before and after the section cracking should be considered to solve the effective prestress of the section by the decompression moment test. The DM test is essentially a process in which the negative moment effect of a cracked section is gradually balanced by the positive moment effect. Since the concrete at the crack can carry the compressive strain, the magnitude, direction, and action point of the negative moment caused by the effective prestress before and after the section cracking remain unchanged. At the same time, the compressive area of the full section (assuming smooth contact surface) and the elastic modulus under the compression remain virtually unchanged. Furthermore, the geometrical, physical, and static factors that affect the section stress balance before and after the section cracking have not changed. Therefore, the negative bending moment of the section caused by the effective prestress will not change before and after the section cracking. On the other hand, the internal force state of the simply supported beam is only related to the load distribution and action position. The total positive moment in the mid-span section under each load level will not change before and after the section cracking. When the section with a closed crack reaches the critical DM state again, the positive and negative bending moments of the closed cracked section balance each other (i.e., equaling each other but acting oppositely). Therefore, it can be known from the principle of mechanics of materials that when the section with a closed crack reaches the critical DM state again, the effective prestress of the strand can be calculated according to 
the parameters of the whole section before cracking, as evidenced by the test results.

\section{Conclusions}

From this study, the following conclusions may be drawn:

(1) Both test and numerical analysis results show that the slope inflection point of the moment-strain change rate curve is much more significant than that of the moment-strain increment method before and after the critical decompression state with the closed cracked section. Since the simply supported beam does not have the redistribution effect of internal forces along the longitudinal direction of the bridge, the internal forces in the section are only related to the load position and distribution. Therefore, the test method proposed in this paper can be used to determine the decompression moment of the section with breathing cracks in a simply supported beam.

(2) Based on the critical decompression retest of the section with closed cracks, this paper proposes an evaluation method for effective prestress of $\mathrm{P} / \mathrm{S}$ strands in the tensile region of the main beam. The proposed method is more reasonable and accurate than the previous one using the downward deflection and crack width of the main beam.

(3) When the total prestress of $\mathrm{P} / \mathrm{S}$ strands in the tensile region is ascertained with the decompression moment of the section with closed cracks, the nonlinear effect of stress on the section can be ignored. However, if the fiber stress increment of the section, caused by the continuous loading after decompression, is analyzed, it is required to consider the coupling effect between prestress and the position change of the neutral axis as well as the flexural rigidity of section.

(4) This method is suitable for evaluating critical decompression moment and effective prestressing force for the side beams of the statically indeterminate bridge beam with closed cracks. In terms of the selection of cross-sections with closed cracks and the arrangement of measuring points, the positions of stressed cracks (nonsurface dry shrinkage cracks) can be marked during the preloading stage of the load test of a real bridge (i.e., the test load not exceeding the critical decompression load of the section), when the micro-cracks near the mid-span section of the side beam reopen. Once the load is removed, the protective layer concrete of the outermost rebars in the tensile zone can be removed artificially at the crack position. And the strain gauge is pasted at the position of the reinforcement across the crack. After that, the normal loading test is carried out in steps.

\section{Nomenclature}

$x$ : The height of the section compression zone

$b$ : The section width

$y_{n}, y_{0}$ : The distance from the lower edge of tensile region to the key axis of the net section or the transformed section

$e_{p n}$, The distance from the resultant force of $\mathrm{P} / \mathrm{S}$ strands

$e_{p 0}$ : to the key axis of the net section or the transformed section

$N_{p 0}$ : The resultant force of effective prestress of $\mathrm{P} / \mathrm{S}$ strands after deducting the stress loss at corresponding phases

$\sigma_{p 0}: \quad$ The $\mathrm{P} / \mathrm{S}$ strand stress

$\sigma_{p c}$ : Stress at the outermost edge of the section concrete tensile zone

$A_{n}$ : The net cross-sectional area of concrete section after deducting the duct

$A_{0}$ : The cross-sectional area of the transformed section

$A_{y}: \quad$ The cross-sectional area of the strand

$\omega_{n}, \omega_{0}$ : The bending modulus of the net section or the transformed section

$I_{n}, I_{0}$ : The moments of inertia of the net section or the transformed section

E: $\quad$ The elasticity modulus of concrete

I: $\quad$ The modified effective flexural stiffness of section

N: $\quad$ The resultant force of effective prestress of $\mathrm{P} / \mathrm{S}$ strands

$f_{\mathrm{e}}$ : The natural frequency, and $I_{\mathrm{g}}$ is the actual flexural stiffness of section

$\varepsilon_{p 0}$ : The effective strain of $\mathrm{P} / \mathrm{S}$ strands when the normal stress of concrete at the c.g. of the resultant force of $\mathrm{P} / \mathrm{S}$ strands in the tensile region is equal to zero

$E_{y}: \quad$ The elasticity modulus of $\mathrm{P} / \mathrm{S}$ strand

$M_{c r}$ : The cracking moment

$f_{t k}$ : The standard concrete axial tensile strength

$\gamma: \quad$ The plastic effect coefficient of concrete in the tensile region.

\section{Data Availability}

The data used to support the findings of this study are available from the corresponding author upon request.

\section{Disclosure}

The information expressed in this paper is opinions solely from the authors.

\section{Conflicts of Interest}

The authors declare that they have no conflicts of interest. 


\section{Acknowledgments}

The authors are grateful for the support from Chinese National Key R\&D Project (No. 2018YFB1600300); National Natural Science Foundation Project (No. 51878059); Shanxi Natural Science Foundation Project (No. 201801D121165, 201801D221216, and 201801D221217); and Shanxi Department of Transportation, Shanxi Province, China (Nos. 20131-06 and 2016-1-22).

\section{References}

[1] Y. Ren and Y. Chen, "Research on damage identification of beam with breathing crack by singular spectrum entropy," Journal of Applied Mechanics, vol. 36, no. 1, pp. 230-266, 2019.

[2] C. G. Karayannis and C. E. Chalioris, "Design of partially prestressed concrete beams based on the cracking control provisions," Engineering Structures, vol. 48, no. Mar., pp. 402-416, 2013.

[3] A. S. Alnuaimi and P. Bhatt, "Direct design of partially prestressed concrete hollow beams," Advances in Structural Engineering, vol. 9, no. 4, pp. 459-476, 2006.

[4] G. P. Osborn, P. J. Barr, D. A. Petty, M. W. Halling, and T. R. Brackus, "Residual prestress forces and shear capacity of salvaged prestressed concrete bridge girders," Journal of Bridge Engineering, vol. 17, no. 2, pp. 302-309, 2012.

[5] J. T. Halsey and R. Miller, "Destructive testing of two fortyyear-old prestressed concrete bridge beams," PCI Journal, vol. 41, no. 5, pp. 84-93, 1996.

[6] N. Bagge, L. J. Nilimaa, and L. Elfgren, "In-situ methods to determine residual prestress forces in concrete bridges," Engineering Structures, vol. 135, no. MAR.15, pp. 41-52, 2017.

[7] D. B. Garber, J. M. Gallardo, D. J. Deschenes et al., "Experimental investigation of prestress losses in full-scale bridge girders," ACI Structural Journal, vol. 112, no. 5, pp. 553-564, 2015.

[8] S. A. Civjan, J. O. Jirsa, R. 1. Carrasquillo, and D. W. Fowler, "Instrument to evaluate remaining prestress in damaged prestressed concrete bridge girders," PCI Journal, vol. 43, no. 2, pp. 62-71, 1998.

[9] A. K. Maji and I. Negret, "Smart prestressing with shapememory alloy," Journal of Engineering Mechanics, vol. 124, no. 10, pp. 1121-1128, 1998.

[10] T. M. Ahlborn, C. K. Shield, and C. W. French, "Full-scale testing of prestressed concrete bridge girders," Experimental Techniques, vol. 21, no. 1, pp. 33-35, 1997.

[11] A. I. Ghorbanpoor, "Magnetic-based NDE of steel in prestressed and post-tensioned concrete bridges," Proceedings of SPIE-The International Society for Optical Engineering, vol. 3400, pp. 343-347, 1998.

[12] P. Cawley and R. D. Adams, "The location of defects in structures from measurements of natural frequencies," The Journal of Strain Analysis for Engineering Design, vol. 14, no. 2, pp. 49-57, 1979.

[13] R. W. Clough and J. Penzien, Dynamic of Structures, McGrawHill, New York, NY, USA, 1982.

[14] M. Saiidi, B. Douglas, and S. Feng, "Prestress force effect on vibration frequency of concrete bridges," Journal of Structural Engineering, vol. 120, no. 7, pp. 2233-2241, 1994.

[15] A. Dall, L. Dezi, K. Sudhir et al., "Prestress force effect on vibration frequency of concrete bridges discussion," Journal of Structural Engineering, vol. 112, pp. 458-460, 1996.
[16] J. M. Housner and K. Belvin, "On the analytical modeling of the nonlinear vibrations of pretensioned space structures," Computers and Structures, vol. 16, no. 124, pp. 339-352, 1983.

[17] A. Miyamoto, K. Nakamura, and H. Nakamura, "Bridge management system and maintenance optimization for existing bridges," Computer-Aided Civil and Infrastructure Engineering, vol. 15, pp. 45-55, 2000.

[18] J.-T. Kim, Y.-S. Ryu, and C.-B. Yun, "Vibration-based method to detect prestress loss in beam-type bridges," Smart Structures and Materials, vol. 5057, no. 9, pp. 559-568, 2003.

[19] S. Li, S. He, and L. Cheng, "Detection and assessment on existing stress of PC girder bridge based on horizontal tension-increment method," Journal of Chang'an University (Natural Science Edition), vol. 32, no. 2, pp. 70-81, 2012.

[20] J. S. Ye, Structure Design Principle, pp. 200-313, China Communications Press, Beijing, China, 2005.

[21] T. P. Fries, "A corrected XFEM approximation without problems in blending elements," International Journal for Numerical Methods in Engineering, vol. 75, no. 5, pp. 503-532, 2008.

[22] D. Ma, H. Duan, Q. Zhang et al., "A numerical gas fracturing model of coupled thermal, flowing and mechanical effects," Computers, Materials \& Continua, vol. 65, no. 3, pp. 21232141, 2020.

[23] D. Ma, H. Duan, W. Liu, X. Ma, and M. Tao, "Water-sediment two-phase flow inrush hazard in rock fractures of overburden strata during coal mining," Mine Water and the Environment, vol. 39, pp. 308-319, 2020.

[24] D. Ma, J. Zhang, H. Duan et al., "Reutilization of gangue wastes in underground backfilling mining: overburden aquifer protection," Chemosphere, vol. 264, no. 1, p. 128400 , 2021.

[25] Z. Chen and S. Zhang, "EM-based monitoring and probabilistic analysis of prestress loss of bonded tendons in PSC beams," Advances in Civil Engineering, vol. 2018, no. 8, 9 pages, Article ID 4064362, 2018.

[26] Q. Lv, Y. Liu, and Y. Ding, "Analyses on prestress loss and flexural performance of the laminated bamboo beam applied with prestressed BFRP sheet," Advances in Civil Engineering, vol. 2019, Article ID 2319814, 13 pages, 2019.

[27] W.-n. Sui, Z.-y. Wang, Z.-h. Zhao, and Z.-f. Wang, "Failure mechanism and mechanical properties of a retard-bonded prestressed concrete girder while curing," Advances in Civil Engineering, vol. 2019, no. 11, 14 pages, Article ID 7153235, 2019.

[28] W.-l. Guo, Z.-j. Han, and L. Zhi-hua, "Performance and status difference experiment before and after reinforcement of PC beam," Journal of the China Railway Society, vol. 39, no. 11, pp. 116-123, 2017.

[29] M. U. Rashid, L. A. Qureshi, and M. F. Tahir, "Investigating flexural behaviour of prestressed concrete girders cast by fibre-reinforced concrete," Advances in Civil Engineering, vol. 2019, no. 4, 11 pages, Article ID 1459314, 2019.

[30] American Concrete Institute, ACI 318M-05 Building Code Requirements for Structural Concrete and commentary, American Concrete Institute, Farmington Hills, MI, USA, 2005.

[31] AASHTO, AASHTO LRFD Bridge Design Specifications, American Association of State Highway and Transportation Officials, Washington, DC, USA, 2014. 
[32] National Standard of the PRC, Code for Design of Concrete Structures GB50010-2010, China Building Industry Press, Beijing, China, 2015.

[33] G. S. Ramaswamy, Modern Prestressed Concrete Design, Pitman, London, UK, 1976.

[34] W.-l. Guo, Z.-j. Han, and Y. Frank Chen, "An improved approach for measuring cracking and decompression moments in prestressed concrete members," Structural Engineering International, vol. 28, no. 1, pp. 71-80, 2018.

[35] ABAQUS/Standard Theory Manual, Hibbitt, Karlsson \& Sorensen, Inc., Plymouth, MI, USA, 2002.

[36] S. Qiu, Application Engineering Examples used by Midas Software, People's Communications Press, Beijing, China, 2011.

[37] S. Xu, G. Zhao, and Y. Liu, "Fracture energy of concrete and its variational trend in size effect studied by using three-point bending beams," Journal of Dalian University of Technology, vol. 31, no. 1, pp. 79-86, 1991.

[38] Z. Guo and X. Shi, Reinforced Concrete Theory and Analyse, Tsinghua University Press, Beijing, China, 2003.

[39] X. Gu, Basic Principles of Concrete Structures, Tongji University Press, Shanghai, China, 2011. 